\title{
Pengaruh Pendidikan Kesehatan Mental Se-Jiwaku terhadap Kecemasan dan Perilaku Impulsif Siswa pada Salah Satu SMA di Yogyakarta: Studi Retrospektif
}

\section{Effect of Se-Jiwaku Mental Health Education on Anxiety and Impulsive Behaviours among Students in One of Senior High School in Yogyakarta: A Retrospective Study}

\author{
Heavysta British Fenderin ${ }^{1}$, Ariani Arista Putri Pratiwi ${ }^{2}$, Intansari Nurjannah ${ }^{3^{*}}$ \\ ${ }^{1}$ Program Studi Ilmu Keperawatan, Fakultas Kedokteran, Kesehatan Masyarakat, dan \\ Keperawatan Universitas Gadjah Mada \\ ${ }^{2}$ Departemen Keperawatan Dasar dan Emergensi, Fakultas Kedokteran, Kesehatan \\ Masyarakat, dan Keperawatan, Universitas Gadjah Mada \\ ${ }^{3}$ Departemen Keperawatan Jiwa dan Komunitas, Fakultas Kedokteran, Kesehatan \\ Masyarakat, dan Keperawatan, Universitas Gadjah Mada
}

\begin{abstract}
Background: The total number of adolescents in the world who have anxiety reaches $31,9 \%$, or as many as 1 in 3 teenagers, when they are 18 years old. In addition to anxiety, problems in the form of messing up/making trouble are also often encountered in school-age children, this is due to their limited ability to provide an assessment of the situation which then gives rise to impulsive behaviour. Health education might be applied to help student in regard to anxiety and impulsive behaviours.

Objective: To determine whether Se-Jiwaku Mental Health Education affects the level of anxiety and impulsive behaviours among students in one of senior high school in Yogyakarta.

Methods: This study used a retrospective study design with a descriptive-analytic approach. There were 14 respondents which consisted of 12 females and 2 males. T-MAS and BIS-11 questionnaire were applied as data collecting instruments. The analytical test used was the non-parametric Wilcoxon analysis to see the change in data from pre-test to post-test due to the influence of the Se-Jiwaku Mental Health Education intervention.

Results: The results of this study was 11 out of 14 respondents experience anxiety. For the impulsivity variable, the response range was between 62-89 with a cut-off point of 30 and a maximum score of 120 , The Wilcoxon test results on the anxiety variable showed a score of 0,077 (more than $p=0,05$ ) and the impulsivity variable showed a sig. 2 tailed number of 0,268 (more than $p=0,05$ )

Conclusion: There is not any effect of Se-Jiwaku Mental Health Education on the level of anxiety and impulsive behaviours in Yogyakarta Senior High School Students who become research respondents.
\end{abstract}

Keyword: anxiety, impulsive behaviours, Sejiwaku mental health education

\begin{abstract}
ABSTRAK
Latar belakang: Total remaja di dunia yang memiliki kecemasan mencapai angka 31,9\% atau sebanyak 1 dari 3 remaja mengalami kecemasan saat berusia 18 tahun. Selain kecemasan, permasalahan berupa mengacau/berbuat onar juga sering ditemui pada anak usia sekolah. Hal ini disebabkan oleh terbatasnya kemampuan dalam memberi penilaian terhadap situasi yang kemudian memunculkan perilaku impulsif. Pendidikan kesehatan dapat diaplikasikan untuk membantu siswa terkait kecemasan dan perilaku impulsif ini.

Tujuan: Untuk mengetahui apakah Pendidikan Kesehatan Mental Se-Jiwaku berpengaruh pada tingkat kecemasan dan perilaku impulsif pada siswa di salah satu SMA di Yogyakarta.

Metode: Penelitian ini menggunakan desain Retrospective Study dengan pendekatan deskriptif analitik. Jumlah responden yang terlibat sebanyak 14 siswa yang terdiri dari 12 perempuan dan 2 lelaki. Instrumen yang digunakan adalah Kuesioner T-MAS dan BIS-11. Uji analisis yang digunakan adalah analisis non-parametrik Wilcoxon untuk melihat perubahan data dari pre-test ke post-test akibat pengaruh intervensi Pendidikan Kesehatan Mental Se-Jiwaku.
\end{abstract}


Hasil: Hasil penelitian mendapati 11 dari 14 responden (78,6\%) mengalami kecemasan sedangkan untuk variabel perilaku impulsif, responden memiliki rentang respon antara 62-89 dengan cut-off poin 30 dan skor maksimal 120. Uji Wilcoxon pada variabel kecemasan menunjukkan skor 0,077 (lebih besar dari $p=0,05$ ) dan pada variabel perilaku impulsif menunjukkan angka sig. 2 tailed sebesar 0,268 (lebih besar dari $p=0,05$ ).

Kesimpulan: Tidak ada pengaruh Pendidikan Kesehatan Mental Se-Jiwaku terhadap tingkat kecemasan dan perilaku impulsif pada Siswa SMA di Yogyakarta yang menjadi responden penelitian ini.

Keyword: kecemasan, perilaku impulsif, Pendidikan Kesehatan Mental Se-Jiwaku

\section{PENDAHULUAN}

Kondisi kesehatan mental pada remaja menjadi salah satu fokus dunia kesehatan saat ini. Diketahui sebanyak 36,7\% anak memiliki setidaknya satu gangguan yang terdiagnosis saat mereka menginjak usia 16 tahun. ${ }^{1}$ Pada kelompok usia 17-19 tahun memiliki tingkat gangguan emosi tertinggi $(14,0 \%)^{2}$ Di Indonesia, penduduk yang berusia 15 tahun ke atas yang mengalami gangguan mental emosional mencapai $6 \%$ dari total penduduk atau sekitar 14 juta jiwa dan jumlah ini meningkat menjadi 9,8\% atau 23 juta jiwa pada 2018. 3,4

Sebanyak 31,9\% remaja mengalami kecemasan atau 1 dari 3 remaja memiliki kriteria kecemasan saat mencapai usia 18 tahun. Prevalensi kecemasan pada remaja sendiri lebih banyak dialami remaja perempuan daripada remaja laki- laki, dengan perbandingan $2: 1 .^{5}$ Permasalahan yang paling sering ditemui pada anak usia sekolah adalah perilaku mengacau/berbuat onar dan kecemasan. ${ }^{6}$ Berbagai riset mengenai bagaimana perkembangan otak manusia semasa remaja menunjukkan hasil yang mencolok bahwa otak remaja belum sepenuhnya berkembang matang hingga mencapai usia 25 tahun. Hal ini menyebabkan pengambilan keputusan dan penilaian yang dilakukan remaja menjadi terbatas. ${ }^{7}$ Selain itu pola pikir remaja cenderung berfokus pada saat ini dibandingkan masa depan, inilah yang membuat keputusan remaja sering kali bersifat impulsif atau spontan.

Promosi kesehatan mental adalah salah satu upaya dalam menanggulangi berbagai masalah kesehatan yang ada, termasuk masalah kesehatan mental. Anak-anak dan remaja menghabiskan waktu mereka lebih banyak di sekolah daripada di tempat lainnya, maka dari itu kegiatan promosi kesehatan di sekolah dinilai lebih efektif dibandingkan di tempat lain. Di Inggris, promosi kesehatan mental merupakan salah satu kunci dari kebijakan kesehatan dengan mengandalkan sekolah sebagai penggerak utamanya. ${ }^{8}$ Beberapa penelitian menunjukkan bahwa promosi kesehatan mental yang dilakukan di sekolah memiliki dampak positif terhadap tingkat kesehatan mental dan well-being siswa di sekolah. Selain itu, kegiatan ini juga terbukti mengurangi tingkat bullying yang terjadi di lingkungan sekolah. ${ }^{9}$

Pendidikan Kesehatan Mental Se-Jiwaku adalah salah satu kegiatan promosi kesehatan mental di sekolah yang merupakan kegiatan pengabdian masyarakat dari staf Departemen Keperawatan Jiwa dan Komunitas pada tahun 2019. Peneliti tertarik untuk meneliti bagaimana 
pengaruh kegiatan Pendidikan Kesehatan Mental Se-Jiwaku yang dilakukan terhadap tingkat kecemasan dan perilaku impulsif pada siswa salah satu SMA di Yogyakarta yang menjadi sekolah binaan dari Fakultas Kedokteran, Kesehatan Masyarakat dan Keperawatan FK-KMK UGM. Hal ini dilakukan karena belum banyak penelitian mengenai pengaruh promosi kesehatan mental di sekolah terhadap tingkat kecemasan dan perilaku impulsif pada siswa SMA. Penelitian ini bertujuan untuk mengetahui pengaruh dari Pendidikan Kesehatan Mental Se-Jiwaku terhadap kecemasan dan perilaku impulsif pada siswa di salah satu SMA di Yogyakarta.

\section{METODE PENELITIAN}

Penelitian ini merupakan penelitian retrospective study dengan pendekatan deskriptif analitik, peneliti menggunakan data sekunder, berupa hasil pengisian kuesioner pre-test dan post-test dalam kegiatan pengabdian masyarakat. Data sekunder yang digunakan adalah hasil pengisian kuesioner yang berjumlah 17 data pre-test dan post-test dari seluruh siswa SMA yang mengikuti kegiatan Pendidikan Kesehatan Se-Jiwaku. Pemilihan 17 siswa dilakukan oleh guru kelas berdasarkan kecenderungan berbuat impulsif atau memiliki tanda kecemasan dan memiliki keluhan keluarga broken home. Adapun kriteria inklusi dari responden adalah dokumen pengisian pre-test dan post-test yang telah diisi lengkap oleh siswa SMA dalam kegiatan Pendidikan Kesehatan Se-Jiwaku. Berdasarkan kriteria inklusi tersebut, terdapat 14 dokumen pre-test dan post-test yang memenuhi kriteria untuk dilakukan analisis.

Instrumen yang digunakan pada kegiatan pengabdian masyarakat untuk pre-test dan post-test adalah Taylor Manifest Anxiety Scale yang terdiri dari 50 pertanyaan dengan opsi Guttman: 1 (ya) dan 0 (tidak), dan Baratt Impulsiveness Score yang terdiri dari 30 pertanyaan dengan skala Likert, dengan skala 1 (tidak pernah), 2 (kadang-kadang), 3 (sering), dan 4 (selalu). Kedua instrumen ini sudah teruji validitas dan reliabilitasnya di penelitian sebelumnya. Untuk instrumen T-MAS, hasil uji validitasnya sebesar 0,72, sedangkan hasil uji reliabilitasnya

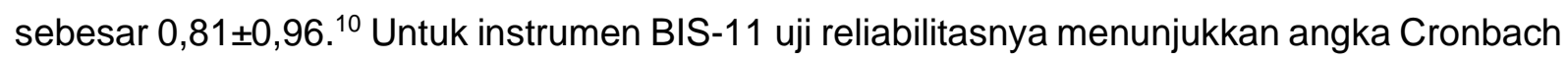
Alpha sebesar 0,80 dan hasil uji validitasnya sebesar $0,61 .{ }^{11}$

Penelitian ini telah mendapatkan kelayakan etik (ethical clearance) dari Komite Etik FKKMK UGM dengan nomor KE-FK-0842-EC-2020. Analisis univariat dilakukan terhadap variabel penelitian secara deskriptif, untuk memberi gambaran distribusi frekuensi dari masingmasing variabel yaitu kecemasan dan perilaku impulsif. Analisis bivariat menggunakan analisis Non-Parametrik Wilcoxon dilakukan untuk melihat perubahan dari skor pre-test dan post-tes yang terjadi akibat intervensi. 


\section{HASIL}

Karakteristik responden pada penelitian ini merupakan siswa kelas 12 di salah satu SMA di Yogyakarta yang berjumlah 14 siswa. Sebanyak 12 responden $(85,7 \%)$ berjenis kelamin perempuan dan 2 responden (14,3\%) berjenis kelamin laki-laki. Berdasarkan hasil data sekunder dari kegiatan pengabdian masyarakat, Pendidikan Kesehatan Se-Jiwaku, tidak terdapat informasi detail terkait karakteristik responden.

Gambaran kecemasan responden ditampilkan pada Tabel 1. Penilaian kategori kecemasan terbagi menjadi cemas (skor $\geq 21$ ) dan tidak cemas (skor $<21$ ). Menurut data pretest, sebanyak 11 responden dikategorikan cemas karena memiliki total skor yang lebih besar dari 21. Kemudian pada data post-test, responden yang mengalami kecemasan menurun jumlahnya menjadi 9 responden. Namun, jika dilihat dari skor per orang, justru mengalami peningkatan.

Tabel 1. Gambaran kecemasan responden sebelum dan sesudah pendidikan kesehatan $(n=14)$

\begin{tabular}{ccccc}
\hline \multirow{2}{*}{$\begin{array}{c}\text { Kode } \\
\text { Responden }\end{array}$} & \multicolumn{2}{c}{ Skor Pre-Test } & \multicolumn{2}{c}{ Skor Post-Test } \\
\cline { 2 - 5 } & Total & Interpretasi & Total & Interpretasi \\
\hline 1 & 17 & tidak cemas & 19 & tidak cemas \\
\hline 2 & 20 & tidak cemas & 19 & tidak cemas \\
\hline 5 & 14 & tidak cemas & 20 & tidak cemas \\
\hline 6 & 23 & cemas & 18 & tidak cemas \\
\hline 7 & 29 & cemas & 30 & cemas \\
\hline 8 & 26 & cemas & 31 & cemas \\
\hline 9 & 28 & cemas & 27 & cemas \\
\hline 10 & 21 & cemas & 19 & tidak cemas \\
\hline 11 & 29 & cemas & 34 & cemas \\
\hline 13 & 30 & cemas & 32 & cemas \\
\hline 14 & 32 & cemas & 35 & cemas \\
\hline 15 & 34 & cemas & 38 & cemas \\
\hline 16 & 29 & cemas & 35 & cemas \\
\hline 17 & 36 & cemas & 35 & cemas \\
\hline
\end{tabular}

Skor penilaian Baratt Impulsiveness Scale memiliki rentang skor 30-120, dengan interpretasi, semakin tinggi skor maka semakin tinggi pula tingkat perilaku impulsif yang dialami responden. Skor BIS-11 ditampilkan pada Tabel 2. Dari Tabel 2 diketahui skor perilaku impulsif paling tinggi pada pre-test adalah 87. Namun, ketika post-test skor tertinggi malah meningkat menjadi 89. Berdasarkan Tabel 2, dapat dilihat bahwa sebanyak 4 responden $(28,57 \%)$ mengalami penurunan skor perilaku impulsif setelah pemberian intervensi dan 1 responden (7,14\%) menunjukkan skor tetap. Sementara 9 responden $(64,28 \%)$ lainnya malah menunjukkan peningkatan skor perilaku impulsif setelah diberikan intervensi Pendidikan Kesehatan Se-Jiwaku.

Hasil analisis data untuk mengetahui pengaruh pendidikan kesehatan terhadap kecemasan dan tingkat perilaku impulsif ditampilkan pada Tabel 3. Uji yang dilakukan adalah uji Wilcoxon, mengingat data kecemasan pre-test adalah terdistribusi normal, sedangkan data 
post-test tidak terdistribusi normal. Sementara itu, data BIS-11 pre-test tidak terdistribusi normal, sedangkan data BIS-11 post-test terdistribusi normal.

Tabel 2. Total skor dan persentase pre-test dan post-test barratt impulsiveness scale $(\mathrm{n}=14)$

\begin{tabular}{ccc}
\hline Kode responden & Skor pre-test & Skor post-test \\
\hline 1 & 87 & 89 \\
\hline 2 & 68 & 69 \\
\hline 5 & 66 & 67 \\
\hline 6 & 69 & 66 \\
\hline 7 & 73 & 67 \\
\hline 8 & 75 & 80 \\
\hline 9 & 64 & 62 \\
\hline 10 & 65 & 73 \\
\hline 11 & 65 & 65 \\
\hline 13 & 69 & 78 \\
\hline 14 & 70 & 79 \\
\hline 15 & 69 & 70 \\
\hline 16 & 83 & 79 \\
\hline 17 & 72 & 73
\end{tabular}

Tabel 3. Hasil uji Wilcoxon pengaruh pendidikan kesehatan mental se-jiwaku terhadap tingkat kecemasan dan perilaku impulsif $(n=14)$

\begin{tabular}{|c|c|c|c|c|c|c|}
\hline \multirow[b]{2}{*}{ Variabel } & \multicolumn{2}{|c|}{ Nilai pre-test } & \multicolumn{2}{|c|}{ Nilai post-test } & \multirow[b]{2}{*}{$\mathbf{Z}$} & \multirow[b]{2}{*}{$p$-value } \\
\hline & Mean \pm SD & $\begin{array}{c}\text { Median } \\
(\text { Min-Max) }\end{array}$ & Mean士SD & $\begin{array}{c}\text { Median } \\
\text { (Min-Max) }\end{array}$ & & \\
\hline Kecemasan & $26,29 \pm 6,45$ & & & $30,50(18-38)$ & $-1,766$ & 0,077 \\
\hline Perilaku impulsif & & $69(64-87)$ & $71,07 \pm 6,73$ & & $-1,108$ & 0,268 \\
\hline
\end{tabular}

Dari hasil analisis yang ditampilkan pada Tabel 3, didapatkan kedua nilai $p$-value lebih besar dari nilai $p=0,05$. Dapat disimpulkan bahwa pemberian Pendidikan Kesehatan Mental Se-Jiwaku tidak berpengaruh terhadap kecemasan dan tingkat perilaku impulsif responden.

\section{PEMBAHASAN}

Dari hasil penelitian ini, responden wanita lebih cenderung mengalami kecemasan lebih tinggi dibanding responden pria. Hal ini disebabkan karena $86 \%$ dari penelitian ini memang wanita. Hal ini sejalan dengan penelitian oleh Wiklund et al. ${ }^{12}$ yang menyebutkan bahwa, responden perempuan yang mengalami kecemasan sebesar $31,5 \%$ dan responden laki-laki hanya sebesar $21,1 \% .^{12}$

Perbedaan yang cukup mencolok di antara jumlah perempuan dan laki-laki yang mengalami kecemasan bukan tanpa alasan, menurut Hyde et al. ${ }^{13}$ perempuan lebih sering mengalami tekanan stres dibanding laki-laki karena kerentanan biologis, afektif, dan kognitif pada perempuan saat berinteraksi dengan peristiwa negatif dalam kehidupan. Neumann et al. ${ }^{14}$ menyebutkan perempuan cenderung memiliki kesulitan yang lebih besar dalam mengatur emosi negatif dibanding laki-laki. Remaja perempuan menunjukkan penolakan emosional yang lebih besar, emosi yang kurang jelas, strategi regulasi emosi yang kurang efektif, serta kesulitan untuk berorientasi pada tujuan, ketika mengalami kesusahan dibandingkan remaja 
laki-laki. ${ }^{14}$ Selain itu, masa pubertas diketahui juga besar kaitannya dengan tekanan emosional perempuan dan berbagai masalah perilaku yang terjadi pada remaja. ${ }^{15,16}$

Berdasarkan variabel perilaku impulsif, hasil penelitian menunjukkan rata-rata skor perilaku impulsif 71,07 poin untuk pre-test dan 72,64 poin dengan skor perilaku impulsif tertinggi dialami oleh responden laki-laki baik pada pre-test maupun post-test dengan skor 87 dan pada responden perempuan skor berkisar 64-83 poin. Skor responden laki-laki dan perempuan yang tidak terpaut jauh menunjukkan bahwa tidak adanya pengaruh gender terhadap perilaku impulsif yang terjadi, hal ini sesuai dengan penelitian oleh Dir et al. ${ }^{17}$ yang menyebutkan bahwa gender tidak memiliki pengaruh signifikan pada perilaku impulsif seseorang. Pada perempuan, kurangnya empati berhubungan dengan verbal aggression, sedangkan pada laki-laki hal ini dikaitkan dengan agresi fisik. Perilaku impulsif biasanya sering terjadi pada remaja dengan masalah penyesuaian sosial, psikologis, dan gangguan psikiatrik. ${ }^{18}$

Namun, dapat dilihat bahwa skor yang didapatkan responden cukup tinggi, dengan patokan batas bawah skor adalah yang paling tidak impulsif yaitu 30 poin, maka skor yang dialami responden cukup menunjukkan perilaku impulsif yang tinggi. Hal ini sesuai dengan penelitian Piko et al. ${ }^{18}$ yang menunjukkan bahwa perilaku impulsif, agresif, dan depresi cenderung lebih sering muncul pada usia remaja. Hal ini berkaitan dengan proses neurodevelopmental selama masa remaja, dengan kata lain peningkatan perilaku mengambil risiko dan peningkatan reaktivitas emosi pada remaja diasosiasikan dengan perkembangan trajektorillintasan daerah subkortikal limbik yang berkaitan dengan daerah prefrontal cortex yang kemudian menghasilkan keputusan personal pada remaja yang sedikit mempertimbangkan kemampuan intelektual dan lebih banyak mempertimbangkan perasaan saat dihadapkan pada situasi pengambilan keputusan.

Hasil penelitian ini menunjukkan pendidikan kesehatan mental Sejiwaku tidak berpengaruh terhadap kecemasan dan perilaku impulsif siswa. Hasil penelitian ini bertolak belakang dengan beberapa penelitian terdahulu, bahwa pemberian edukasi kesehatan mental baik promosi maupun intervensi, berpengaruh positif pada tingkat kecemasan dan perilaku impulsif seseorang. ${ }^{9,19,20} \mathrm{Hal}$ tersebut bisa disebabkan beberapa faktor seperti durasi kegiatan intervensi yang hanya dilakukan satu kali. Hal ini sejalan dengan penelitian Panter-Brick ${ }^{21}$ yang menyebutkan bahwa intervensi jangka pendek tidak dapat menyelesaikan masalah kompleks yang berhubungan dengan masalah di keluarga seperti kekerasan atau perundungan (bullying) di masyarakat, walaupun intervensi ini berbasis sekolah.

Menurut Fazel et al. ${ }^{19}$ intervensi akan semakin efektif bila dilakukan lebih terstruktur dan memiliki durasi yang lebih panjang, selain itu intervensi yang diberikan di sekolah itu sebaiknya praktis, mudah dilaksanakan, dan dapat diukur. Selain itu, intervensi juga harus bisa menghubungkan pendidikan dan sektor kesehatan, yang tidak hanya melibatkan staf sekolah, 
namun juga keluarga dan komunitas karena mereka juga merupakan komponen penting dalam layanan kesehatan mental di sekolah. ${ }^{19}$ Penelitian yang dilakukan Wells et al. ${ }^{22}$ menunjukkan adanya perubahan yang signifikan pada murid dengan program yang dilakukan secara berkesinambungan selama minimal satu tahun. Dalam penggalian informasi untuk mengetahui masalah dan intervensi yang sesuai bagi responden, diperlukan pertanyaan mengenai situasi dan latar belakang responden, seperti bagaimana kondisi keluarga responden, apakah terlibat atau menyaksikan kekerasan, atau melakukan tindak kriminal, dan sebagainya. $^{23}$

Pendidikan Kesehatan Mental Se-Jiwaku diberikan dengan metode ceramah dan praktik terapi komplementer Su-Jok, pada responden target. Menurut penelitian yang dilakukan Calear ${ }^{24}$ program intervensi dan pencegahan yang berbasis selektif di sekolah, dapat efektif untuk mengatasi kesulitan perilaku tertentu, masalah pada siswa dengan risiko (seperti perceraian orang tua), dan masalah siswa dengan kecemasan atau gangguan depresi. Intervensi berupa Su-Jok yang diberikan selain pendidikan kesehatan mental, juga tidak menunjukkan perubahan perilaku pada responden, sebab waktu intervensi hanya dilakukan sekali dan tidak ada observasi lanjutan secara rutin. Hal ini sesuai dengan penelitian oleh Corrales $^{25}$ yang menunjukkan adanya perubahan pada responden yang rutin mengikuti perawatan selama 2 minggu. Sebaliknya, pasien yang hanya kadang-kadang mengikuti perawatan, tidak menunjukkan perubahan.

Kurangnya keterlibatan elemen sekolah dalam pelaksanaan program ini juga dapat menimbulkan tidak efektifnya program yang dijalankan. Hal ini sejalan dengan penelitian Catalano et $a .^{26}$ yang menyebutkan bahwa penghambat dalam berhasilnya suatu program promosi kesehatan mental yaitu lemahnya keterlibatan dari seluruh lapisan sekolah seperti guru, konselor, dan staf pembantu. Program-program yang dilaksanakan pada penelitian lain, rata-rata melibatkan guru dan ahli dari luar sekolah yang sebelumnya sudah terlatih dalam hal classroom-based mental health program, sehingga penyampaian dan pelaksanaan program telah disesuaikan khusus untuk remaja sekolah. ${ }^{20}$ Selain itu, faktor yang berpengaruh pada implementasi program promosi kesehatan di sekolah yaitu prioritas stakeholder terhadap fokus intervensi dan ketertarikan terhadap outcome yang diharapkan. ${ }^{19}$

Selain itu, ada faktor lain yang dapat menjadi hambatan dalam keberhasilan program promosi kesehatan mental yaitu faktor individu seperti stigma, kurangnya perilaku mencari bantuan, status kesehatan mental, faktor risiko parenting, faktor komunitas (geografi dan lokasi sosial), dan sistem kegiatan seperti pendanaan, waktu tunggu, kesediaan tenaga profesional terlatih, dan perencanaan level layanan. ${ }^{23}$ Namun dalam penelitian ini, data sekunder yang digunakan tidak menjelaskan kondisi responden secara detail, sehingga hal ini dapat menjadi bahan pemikiran untuk penelitian selanjutnya. 
Penelitian ini merupakan penelitian retrospektif deskriptif yang hanya menggambarkan pengaruh dari Pendidikan Kesehatan Mental Se-Jiwaku terhadap tingkat kecemasan dan perilaku impulsif pada siswa salah satu SMA di Yogyakarta, berdasarkan data pengisian kuesioner yang sudah ada sebelumnya, tanpa meneliti variabel lain. Kuesioner yang digunakan pun hanya mengukur kecemasan dan perilaku impulsif, tanpa ada wawancara atau data kualitatif yang dapat digunakan untuk menggali lebih dalam faktor-faktor yang dapat berpengaruh, sehingga hasil penelitian ini tidak dapat menggambarkan pengaruh dari Pendidikan Kesehatan Mental terhadap kecemasan dan perilaku impulsif secara utuh.

\section{KESIMPULAN DAN SARAN}

Pendidikan Kesehatan Mental Se-Jiwaku tidak memiliki dampak yang signifikan terhadap perilaku impulsif dan tingkat kecemasan siswa di salah satu SMA di Yogyakarta. Pada penelitian selanjutnya, disarankan agar penelitian dilakukan dengan lingkup yang lebih luas, sehingga dapat melihat pengaruh dari pendidikan kesehatan terhadap kecemasan dan perilaku impulsif.

\section{UCAPAN TERIMA KASIH}

Ucapan terima kasih peneliti sampaikan kepada semua pihak yang telah membantu dan terlibat dalam penelitian ini.

\section{DAFTAR PUSTAKA}

1. Copeland WE, Angold A, Shanahan L, Costello EJ. Longitudinal Patterns of Anxiety From Childhood to Adulthood: The Great Smoky Mountains Study. J Am Acad Child Adolesc Psychiatry [Internet]. $2014 \quad$ Jan; $53(1): \quad 21-33 . \quad$ Available from: https://linkinghub.elsevier.com/retrieve/pii/S0890856713006989

2. The National Health Service. Mental Health of Children and Young People in England, 2017 [PAS] - NHS Digital. England; 2018.

3. Kementerian Kesehatan Republik Indonesia. Riset Kesehatan Dasar Nasional 2013 (RISKESDAS 2013). Kementerian Kesehatan Republik Indonesia; 2013.

4. Kementerian Kesehatan Republik Indonesia. Riset Kesehatan Dasar Nasional 2018 (RISKESDAS 2018). Kementerian Kesehatan Republik Indonesia; 2018.

5. Twenge JM. Time Period and Birth Cohort Differences in Depressive Symptoms in The U.S., 19822013. Soc Indic Res [Internet]. 2015 Apr 5; 121(2): 437-54. Available from: http://link.springer.com/10.1007/s11205-014-0647-1

6. Costello EJ, Egger H, Angold A. 10-Year Research Update Review: The Epidemiology of Child and Adolescent Psychiatric Disorders: I. Methods and Public Health Burden. J Am Acad Child Adolesc Psychiatry [Internet]. 2005 Oct; 44(10): 972-86. Available from: https://inkinghub.elsevier.com/retrieve/pii/S0890856709617597

7. Giedd JN, Blumenthal J, Jeffries NO, Castellanos FX, Liu H, Zijdenbos A, et al. Brain Development during Childhood and Adolescence: A Longitudinal MRI study. Nat Neurosci [Internet]. 1999 Oct; 2(10): 861-3. Available from: http://www.nature.com/articles/nn1099_861

8. Department of Health. The Government's Expenditure Plans 2001-2002 to 2003-2004 and Main Estimates 2001-2002. London; 2001.

9. Kuyken W, Weare K, Ukoumunne OC, Vicary R, Motton N, Burnett R, et al. Effectiveness of The Mindfulness in Schools Programme: Non-Randomised Controlled Feasibility Study. Br J Psychiatry [Internet]. $2013 \quad$ Aug 2; 203(2): 126-31. Available from: https://www.cambridge.org/core/product/identifier/S0007125000067532/type/journal_article

10. Kendall E. The Validity of Taylor's Manifest Anxiety Scale. J Consult Psychol [Internet]. 1954; 18(6): 429-32. Available from: http://doi.apa.org/getdoi.cfm?doi=10.1037/h0057760 
11. Reise SP, Moore TM, Sabb FW, Brown AK, London ED. The Barratt Impulsiveness Scale-11: Reassessment of Its Structure in A Community Sample. Psychol Assess [Internet]. 2013 Jun; 25(2): 631-42. Available from: http://doi.apa.org/getdoi.cfm?doi=10.1037/a0032161

12. Wiklund M, Malmgren-Olsson E-B, Öhman A, Bergström E, Fjellman-Wiklund A. Subjective Health Complaints in Older Adolescents are Related to Perceived Stress, Anxiety and Gender - A CrossSectional School Study in Northern Sweden. BMC Public Health [Internet]. 2012 Dec 16; 12(1): 993. Available from: https://bmcpublichealth.biomedcentral.com/articles/10.1186/1471-2458-12993

13. Hyde JS, Mezulis AH, Abramson LY. The ABC's of Depression: Integrating Affective, Biological, and Cognitive Models to Explain The Emergence of The Gender Difference in Depression. Psychol Rev [Internet]. 2008 Apr; 115(2): 291-313. Available from: http://doi.apa.org/getdoi.cfm?doi=10.1037/0033-295X.115.2.291

14. Neumann A, van Lier PAC, Gratz KL, Koot HM. Multidimensional Assessment of Emotion Regulation Difficulties in Adolescents Using the Difficulties in Emotion Regulation Scale. Assessment [Internet]. 2010 Mar 14; 17(1): 138-49. Available from: http://journals.sagepub.com/doi/10.1177/1073191109349579

15. Lien L, Dalgard F, Heyerdahl S, Thoresen M, Bjertness E. The Relationship between Age of Menarche and Mental Distress in Norwegian Adolescent Girls and Girls from Different Immigrant Groups in Norway: Results from An Urban City Cross-Sectional Survey. Soc Sci Med [Internet]. 2006 Jul; 63(2): 285-95. Available from: https://linkinghub.elsevier.com/retrieve/pii/S0277953606000062

16. Stattin H, Kerr M, Skoog T. Early Pubertal Timing and Girls' Problem Behavior: Integrating Two Hypotheses. J Youth Adolesc [Internet]. 2011 Oct 17; 40(10): 1271-87. Available from: http://link.springer.com/10.1007/s10964-011-9696-9

17. Dir AL, Coskunpinar A, Cyders MA. A Meta-Analytic Review of The Relationship between Adolescent Risky Sexual Behavior and Impulsivity Across Gender, Age, and Race. Clin Psychol Rev [Internet]. 2014 Nov; 34(7): 551-62. Available from: https://linkinghub.elsevier.com/retrieve/pii/S0272735814001330

18. Piko BF, Pinczés T. Impulsivity, Depression and Aggression among Adolescents. Pers Individ Dif [Internet]. $2014 \quad$ Oct; 69 : 33-7. Available from: https://linkinghub.elsevier.com/retrieve/pii/S019188691400292X

19. Fazel M, Patel V, Thomas S, Tol W. Mental Health Interventions in Schools in Low-Income and Middle-Income Countries. Vol. 1, The Lancet Psychiatry. Elsevier Ltd; 2014. p. 388-98.

20. Barry MM, Clarke AM, Jenkins R, Patel V. A Systematic Review of The Effectiveness of Mental Health Promotion Interventions for Young People in Low and Middle Income Countries. BMC Public Health [Internet]. 2013 Dec 11; 13(1): 835. Available from: http://bmcpublichealth.biomedcentral.com/articles/10.1186/1471-2458-13-835

21. Panter-Brick C, Goodman A, Tol W, Eggerman M. Mental Health and Childhood Adversities: A Longitudinal Study in Kabul, Afghanistan. J Am Acad Child Adolesc Psychiatry [Internet]. 2011 Apr; 50(4): 349-63. Available from: https://linkinghub.elsevier.com/retrieve/pii/S0890856710009354

22. Wells J, Barlow J, Stewart-Brown S. A Systematic Review of Universal Approaches to Mental Health Promotion in Schools. Health Educ [Internet]. 2003 Aug; 103(4): 197-220. Available from: https://www.emerald.com/insight/content/doi/10.1108/09654280310485546/full/html

23. Betancourt TS, Agnew-Blais J, Gilman SE, Williams DR, Ellis BH. Past Horrors, Present Struggles: The Role of Stigma in The Association between War Experiences and Psychosocial Adjustment among Former Child Soldiers in Sierra Leone. Soc Sci Med [Internet]. 2010 Jan; 70(1): 17-26. Available from: https://linkinghub.elsevier.com/retrieve/pii/S0277953609006297

24. Calear AL, Christensen H. Systematic Review of School-based Prevention and Early Intervention Programs for Depression. J Adolesc [Internet]. 2010 Jun; 33(3): 429-38. Available from: https://linkinghub.elsevier.com/retrieve/pii/S0140197109001006

25. Corrales O. Su-Jok Therapy in Patients with Anxiety Dad, Seen in Consultation at The Community Center of Arroyo Naranjo Mental Health. "Julio Trigo López ", City of Havana, Cuba; 2008.

26. Catalano RF, Fagan AA, Gavin LE, Greenberg MT, Irwin CE, Ross DA, et al. Worldwide Application of Prevention Science in Adolescent Health. Vol. 379, The Lancet. Elsevier B.V.; 2012. p. 165364. 